\title{
Gunawardenea, a new genus of squat leafhoppers from Western Australia, with description of two new species (Hemiptera: Cicadellidae: Deltocephalinae)
}

\author{
Murray J. Fletcher' and Melinda L. Moir ${ }^{2}$ \\ 'Orange Agricultural Institute, NSW Department of Primary Industries, \\ Forest Road, Orange, New South Wales 2800, Australia \\ School of Botany, University of Melbourne, Parkville, Melbourne, \\ Victoria 3000, Australia. Email: murray fletcher@dpi.nsw.govau
}

\begin{abstract}
The new genus Gmanaminen gen. nov. is described for two leathopper species from the arid zone of Western Australia, G. limnat sp. now. from Barrow Island and G. pulchra sp. nov. from the Gibson Desert and Lorna Glen Station. The genus is placed in the deltocephaline tribe Athysanini. Given the lack of functional wings for both species within the genus and the current restricted distributions for each species, both are likely to be short-range endemics.
\end{abstract}

\section{INTRODUCTION}

Recent surveys of Barrow Island, off the northwestern coast of Western Australia, have revealed a number of novel forms of Auchenorrhyncha. A new species of Idiocerinae from the island, Zaletta webbi Fletcher 2007, was published by Fletcher (2007) and a new Euacanthella Evans 1938, by Fletcher (2008). New taxa of Eurybrachidae have been recognised by Jerome Constant (J. Constant, pers. comm. 2007) and the island also has undescribed species of Alleloplasis Waterhouse 1839 (Tropiduchidae: Gaetuliini), Lipocallia Kirkaldy 1906, and Bilbilicallia Jacobi 1928 (Nogodinidae: Lipocalliini), Caliscelidae and Athysanini (Cicadellidae: Deltocephalinae) (Fletcher, unpublished data). All may be restricted to the island which, at approximately $230 \mathrm{~km}^{2}$ qualifies within the $10,000 \mathrm{~km}^{2}$ definition for a short-range endemic species (Harvey 2002). A new genus is described herein with two species, one from Barrow Island and the other from within and near the Gibson Desert, Western Australia. The genus is placed in the tribe Athysanini.

\section{MATERIALS AND METHODS}

The specimens examined here were collected in wet pitfall traps or vacuum/suction samples, subsequently removed from any solutions and pinned. Male genitalia were dissected for examination and description. Specimens were examined under Leitz TS microscope, and images were photographed through a Zeiss Stemi SV8 microscope, using an Agfa ePhoto 1680 digital camera. Illustrations were prepared using
Photoshop(R) from pencil originals scanned with HP Scanjet $7400 \mathrm{C}$ scanner using the technique described in Fletcher (2008).

The following abbreviations have been used in this paper: ASCU, NSW Agricultural Scientific Collections Unit, Orange, New South Wales; WAM, Western Australian Museum, Perth, Western Australia. The list of abbreviations given after the site number of Barrow Island localities provides information on collection details. "AIR" indicates that the site was near the island's airport, "DHC" means diurnal hand collecting and "SUC" means collected by suction sampler. In addition, "R2" means that this sample was part of the second survey undertaken on the island and "AL" means that all samples collected at this site were pooled. Sites 52 and 109 have Triodia wiseana with leaf litter from Triodia and Acacia, and site 63 has Triodia angusta, again with litter from Triodia and Acacia (S. Callan, pers. comm. 2007).

The site number for the Gibson Desert locality provides information on collection details. Site $11 \mathrm{~A}$ in the Gibson Desert was dominated by mulga (Acacio aneura) woodland over spinifex (Triodia shimzii and T. basedowii) grasslands burnt more than 40 years previously (B. Ward, pers. comm. 2008). Similarly the dominant vegetation at Lorna Glen Station, Bullimore land system site 4 consisted of mulga woodlands with an understorey of spinifex (T. basedowii) (Owen 2004). Specimens from these localities have been donated from the private collection of the second author. 


\section{SYSTEMATICS}

Family Cicadellidae Latreille 1825

Subfamily Deltocephalinae Dallas 1870

Tribe Athysanini Van Duzee 1892

Gunawardenea gen. nov.

\section{Type species}

Gunawardenea linnaei sp. nov.

\section{Description}

Short, squat, brachypterous leafhoppers. Face evenly convex with anteclypeus widening towards apex. Frontoclypeus ovate, encroaching onto dorsum of head with ocelli small, situated dorsally on internal side of laterofrontal sutures, separated from each eye by three or four ocellar diameters. Vertex approximately as wide as a single eye. Vertex transversely wrinkled between ocelli but otherwise smooth. Pronotum clearly wider than head across eyes, very short, obscurely transversely wrinkled, lacking postocular transverse carina. Scutellum shagreen. Tegmen very short, quadrate, venation indicated by dark brown pigmentation. Hind wings absent. Fore tibia with four macrosetae in outer row and single subapical macroseta on inner margin. Fore femur with ventral row of six short macrosetae on basal half and outer row of six macrosetae on apical half, with an additional subapical pair plus 2 subapical dorsal macrosetae. Mid tibia with $4+3$ macrosetae on outer margins. Hind tibia with 9-10 large macrosetae on anterior margin with intercalary row of short macrosetae and 7-8 large macrosetae on external margin alternating with 1-2 shorter macrosetae. Hind femoral setal formula $2+2+1$. Male genitalia: pygofer incurved posteriorly so that lateral margins meet medially. Anal segment short, surrounded by pygofer, with anterior margins slightly sclerotised and extending ventrally on either side of aedeagus. Subgenital plates free, short. Paramere narrow, apically bluntly rounded or acute. Connective thin, Y-shaped with long stalk and short arms. Aedeagus long, mounted at angle to connective, folded at midlength and articulating laterally with ventral extensions of anal segment. Female: Pygofer tubular, tapering towards apex, with strong setae along ventral margin and around apex. First valvulae finely longitudinally strigate on upper half, second valvulae robust, upper margin dark sclerotised with two dorsal prominences on basal half, evenly toothed over apical half, with reticulate sculpturing distally.

\section{Etymology}

The generic name, which is feminine, is derived from Nihara Gunawardene (Curtin University,
WA), who collected the type specimen of $G$. pulchra sp. nov. thereby bringing this genus to our attention.

\section{Remarks}

The genus Gunawardenea is placed in the tribe Athysanini of the Deltocephalinae on the basis of the $Y$-shaped connective and the structure of the head. It is differentiated from other Athysanini genera by the lack of hind wings, reduced forewings and the structure of the male genitalia, in particular the ventral extensions of the anal segment associated with the aedeagus and the medially angled aedeagus. The short vertex of even length throughout and bearing transverse dark markings and the narrow width of the head relative to the width of the pronotum are also distinctive features. Other brachypterous Australian leafhoppers such as species of Horouta Knight 1975 (tribe Deltocephalini) and Goniagnathus Fieber 1866 (Goniagnathini) can be differentiated from Gunawardenea on the basis of the male genitalia and in the width of the head. Species of Goniagnathus have the subgenital plates united to form a single plate while Horouta species all have a distinctive aedeagus structure with the shaft extending posteriorly before curved dorsally and bearing one or two pairs of basal processes. Also, species of Horouta and Goniagnathus all have the head as wide as the pronotum and the vertex distinctly longer in the midline than against the eyes.

\section{Gunawardenea linnaei sp. nov.}

Figures 1-3, 8-13

\section{Material examined}

Holotype

Australia: Western Australia: đ, Barrow Island, 205' $01^{\prime \prime}$, $115^{\circ} 24^{\prime} 19^{\prime \prime} \mathrm{E}, 24$ April 2005, S. Callan "site 52 (R2 AIR SUC AL)" (WAM Entomology Registration No. 71139).

\section{Paratypes}

Australia: Western Australia: $1 \delta$, same data as holotype (ASCU); $1 \delta$, same data as holotype but "site 109 (R2 AIR DHC AL)" (ASCU); 1 d, Barrow Island, 20 $47^{\prime} 38^{\prime \prime S}, 115^{\circ} 27^{\prime} 24^{\prime \prime} \mathrm{E}, 17$ May 2005, S. Callan "site 63 (R2 017 SUC AL) (ASCU); 1 o, same data (WAM Entomology Registration No. 71141).

\section{Diagnosis}

Gunawardenea limnaei differs from $G$. pulchra by the structures of the male genitalia and by the markings on the vertex and frons. G. pulchra has two transverse bands on the vertex, the anterior being interrupted medially, and a series of transverse black bands on either side of the frons 


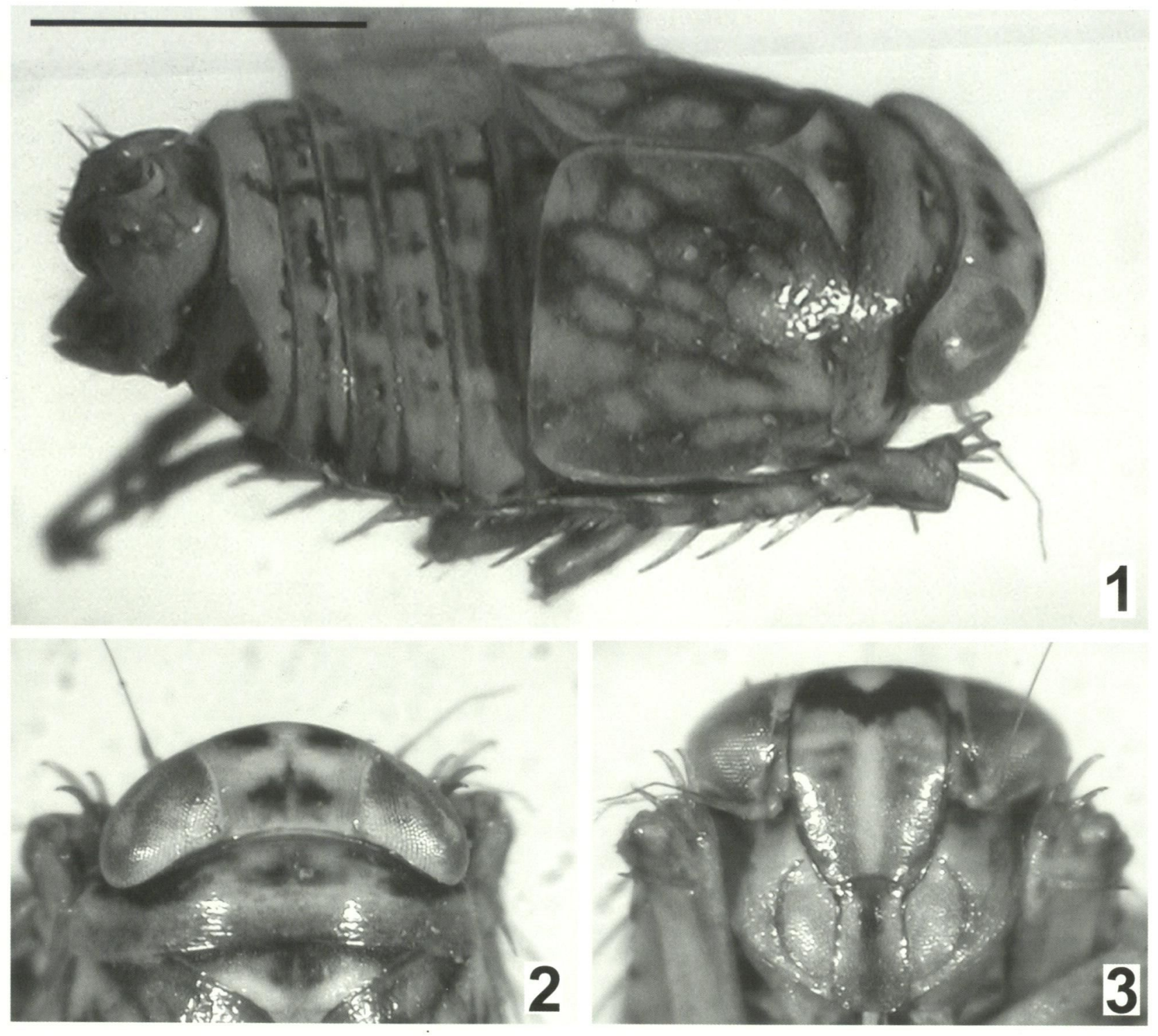

Figures 1-3 Gunawardenea linnaei sp. nov., male paratype from Site 52: 1, habitus; 2, dorsum; 3, face. Scale line = $1 \mathrm{~mm}$.

while in G. linnaei the bands on the vertex are more obscure with the anterior markings linked by a broadly $\mathrm{V}$-shaped band on the upper part of the frons, this marking absent from G. pulchra.

\section{Description}

Total length: male (Figure 1) $(\mathrm{n}=3)$ 2.65-2.95 mm $($ mean=2.82 $\mathrm{mm})$; female unknown.

Colour: Ventrally pale brown with scattered dark markings. Face (Figure 3) light brown with darker markings on anteclypeus and frontoclypeus and a broad V-shaped black band submarginally and extending dorsally to level with ocelli. Vertex (Figure 2) pale brown with anterior dark marks and a pair of obscure black spots medially on posterior half. Pronotum (Figure 2) pale brown with transverse darker markings on anterior half. Tegmen (Figure 1) whitish with chocolate brown veins. Legs pale brown, apically dark brown with subapical dark brown spot on femur and dark brown spots along tibia. Abdomen pale brown with transverse dark brown line on each side of midline which is marked with broad brown longitudinal mark forming interrupted median line along abdomen. Pregenital segment longer than preceding segments, with extensive area on either side of genital capsule pale brown with large dark brown spot on either side. Genital capsule light brown with similar dark brown spot on either side facing posteriorly.

Male genitalia: Pygofer (Figure 8) wrapped around anal segment with lateral margins contiguous posteriorly, broadly rounded with convex protrusion ventrally near base against which subgenital plates rest. Apical lobes with group of short macrosetae and 4-5 stout macrosetae in curved row from base of anal segment towards ventral protrusion. Subgenital 

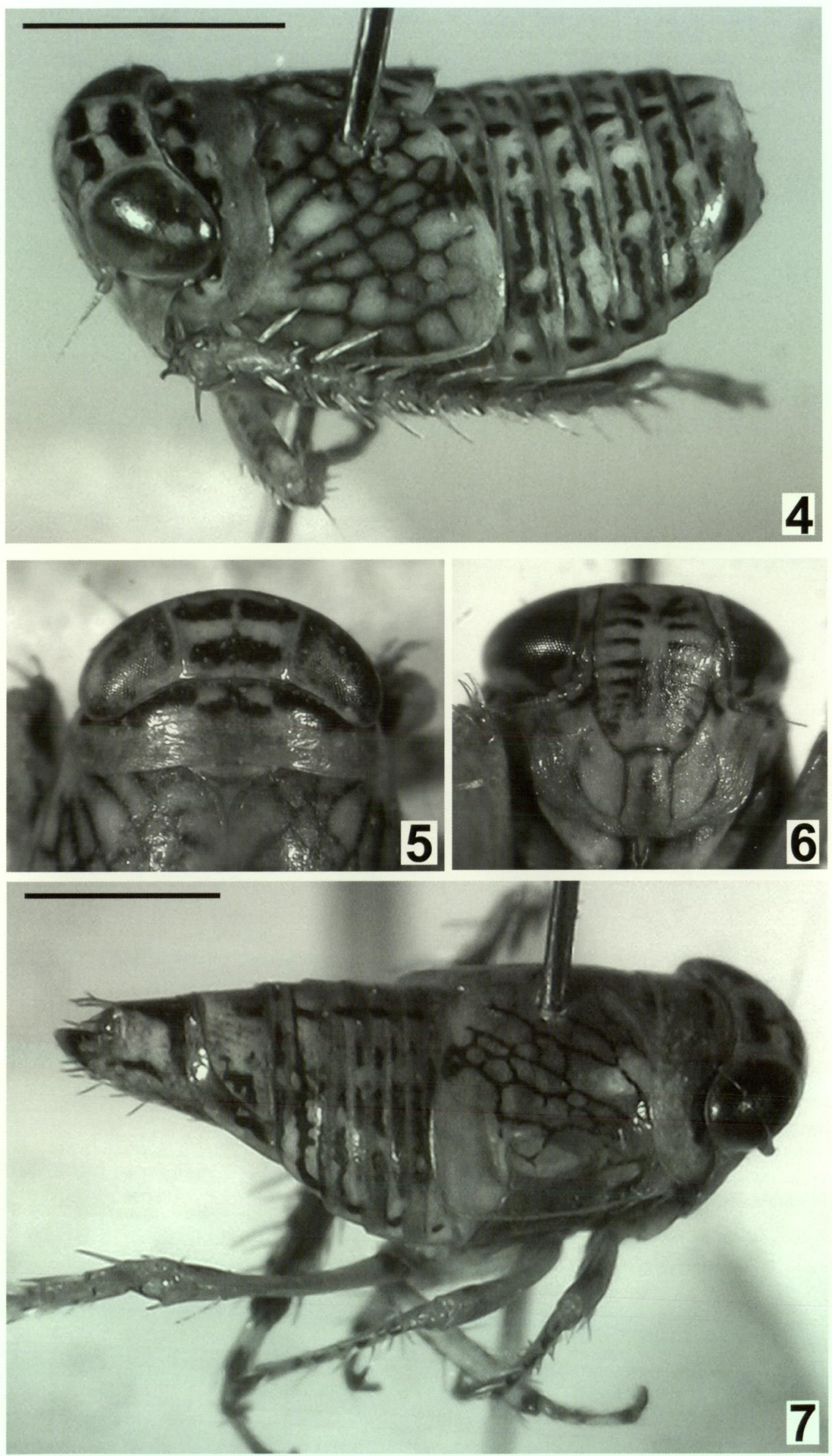

Figures 4-7 Gunawardenea pulchra sp. nov., holotype: 4, habitus; 5, dorsum; 6, face; 7, female paratype, habitus. Scale line $=1 \mathrm{~mm}$. 

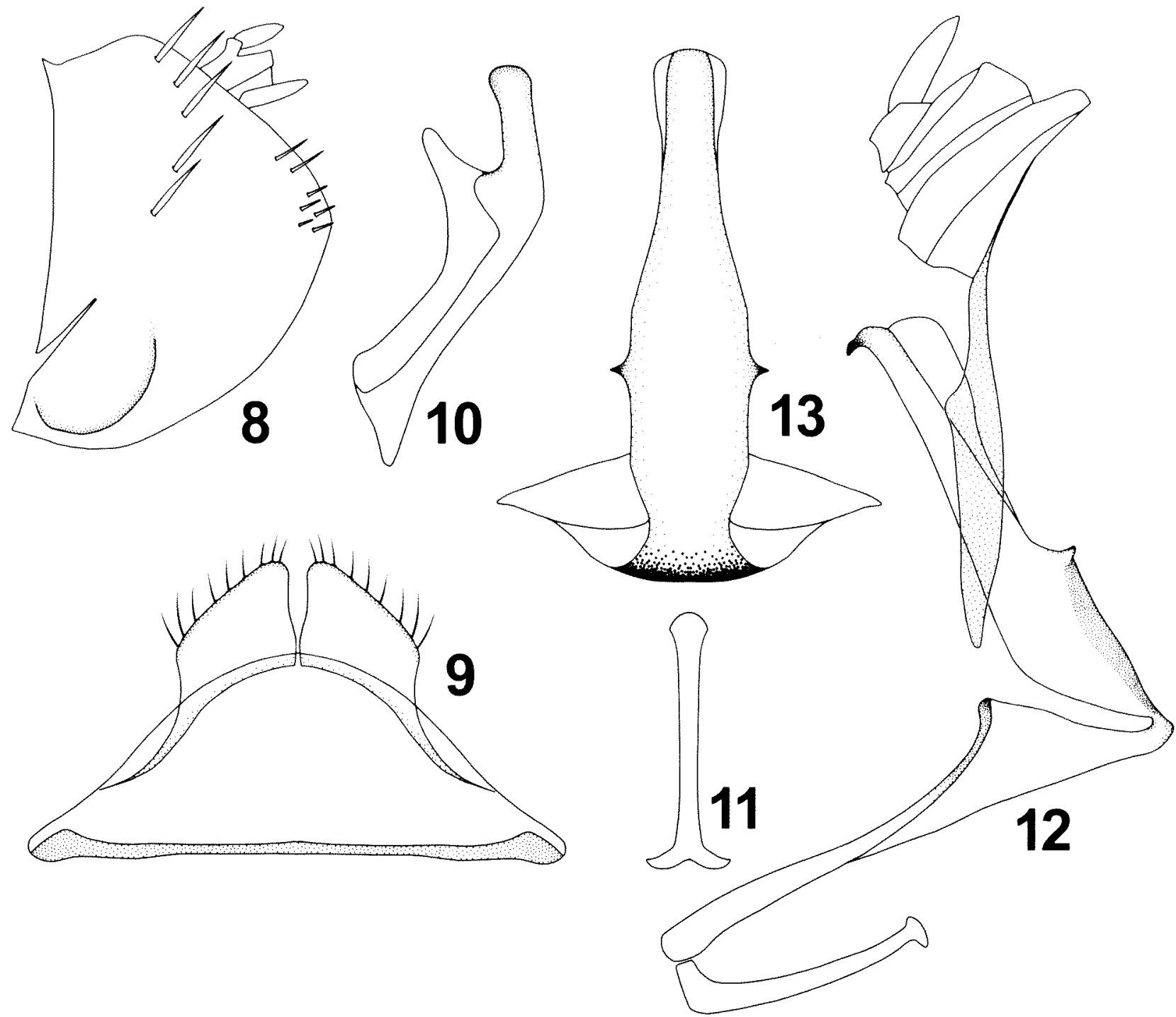

Figures 8-13 Gunawardenen limnat sp. nov: 8, pygofer; 9, pregenital stemite and subgenital plates; 10, paramere; 11, connective; 12, aedeagus and connective, lateral view with anal segment; 13, aedeagus, apical section, posterior view.

plates (Figure 9) short, obliquely truncate, apical margin lined with evenly spaced hair-setae. Parameres (Figure 10) narrow with longish apical process apically rounded, lateral shoulder well developed. Connective (Figure 11) simple with very short lateral arms and long stem. Aedeagus (Figures 12-13) in two sections angled at about 90 degrees to each other. Basal section articulated with connective at base then broadening to lateral knob on each side before narrowing to connection with apical section, which is straight, lateral triangular prominence on basal third, and apex recurved to form apical hook. Gonopore apical. Base of anal segment extending nearly to base of apical aedeagal section on each side (Figure 12).

\section{Etymology}

This species is named in honour of Carolus Linnaeus to mark the $250^{\text {th }}$ anniversary of the $10^{\text {th }}$ edition of his Systema Naturae (Linnaeus 1758) in which binomials were introduced for animal species.

\section{Gunawardenea pulchra sp. nov.}

Figures 5-7, 14-19

\section{Material examined}

Holotype

Australia: Western Australia: $\delta$, Gibson Desert, site 11A, 24.42'36"S, 124.4602"E, August 2002, N. Gunawardene, pitfall trap (WAM Entomology Registration No. 71140).

\section{Paratypes}

Australia: Western Australia: 1 o Bullimore land system, site 4, Lorna Glen Station, 26 12'46"S, $121^{\circ} 06^{3} 32^{\prime \prime}$, March-May 2004, M.L. Moir, pitfall 


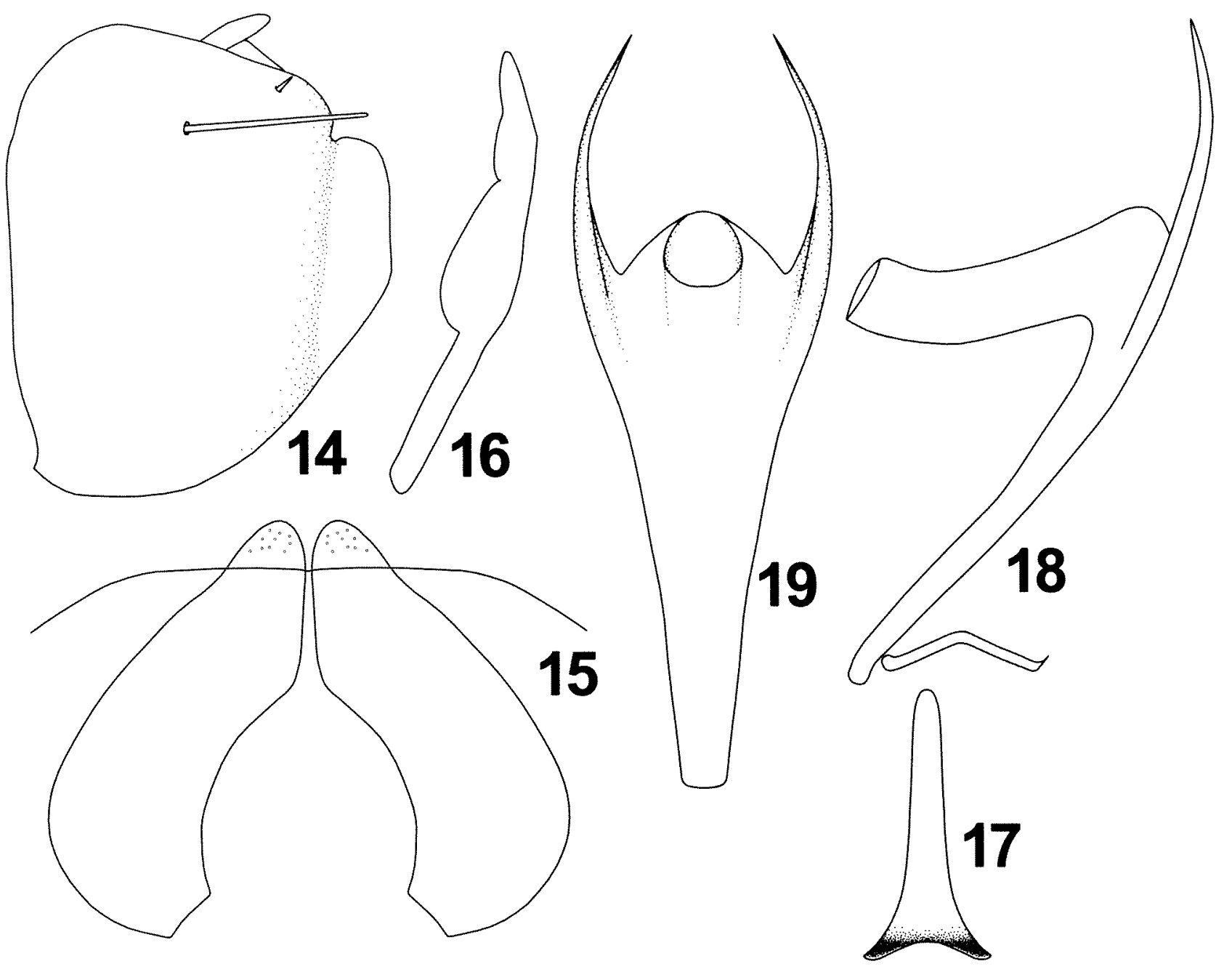

Figures 14-19 Gunawardenea pulchra, sp. nov.: 14, pygofer; 15, subgenital plates with indication of margin of seventh sternite; 16, paramere; 17, apical section of connective; 18, aedeagus and connective, lateral view; 19 , aedeagus, posterior view.

trap (ASCU); 1 \%, same data (WAM Entomology Registration No. 71142).

\section{Diagnosis}

Gunawardenea pulchra differs from G. linnaei by the shape of the aedeagus and the markings on the vertex and frons (see notes under G. linnaei).

\section{Description}

Total length: male (Figure 5) $(\mathrm{n}=2) 2.9 \mathrm{~mm}$; female (Figure 7) $(\mathrm{n}=1) 3.8 \mathrm{~mm}$.

Colour: Face (Figure 6) pale yellow brown with sutures and muscle impressions finely marked in black or dark brown. Vertex (Figure 5) with two broad transverse bands not reaching eye on either side and linked in midline. Pronotum (Figure 5) pale brown with irregular dark markings on anterior half, greyish brown posteriorly. Tegmen (Figures 5 and 7) yellow brown, whitish towards costal margin, with veins marked with dark brown except for costal veins which are reddish. Venter grayish brown, darker laterally. Legs pale brown with dark brown spots on tibia, tarsi dark brown. Inner margin of hind tibia dark brown throughout. Abdomen yellow brown with dark transverse barring laterally and single elongate dot in midline of each segment.

Male genitalia: Seventh segment elongated, extending posteriorly to cover most of anal segment, pygofer and subgenital plates. Pygofer (Figure 14) rounded posteriorly, inrolled, bearing single large setae at midlength towards dorsal margin and small stubby seta close to dorsal margin just beyond level of anal segment. Subgenital plates (Figure 15) rounded, medially concave, lacking setae, small dimples on apex exposed beyond seventh segment. Parameres (Figure 16) elongate, narrow, with lateral shoulder 
not well developed, apically bluntly acute. Connective (Figures 17 and 18) thin, bent twice in lateral view, articulated with base of aedeagus at acute angle (Figure 18), lateral arms very short (Figure 17). Aedeagus (Figures 18 and 19) with basal section narrow in lateral view (Figure 18) with tubular apical section mounted at greater than right angle to basal section. In posteroventral view (Figure 19), basal section widens gradually towards apex, lateral margins extending well beyond medial section to form two finely curved linear processes on either side beyond base of apical section which is tubular to apical gonopore.

\section{Etymology}

The specific name pulchra ( $L$. = "beautiful") reflects the delicate colouration of these insects.

\section{DISCUSSION}

The two species of this genus appear restricted to arid habitats and all specimens were collected in locations dominated by spinifex (Triodia spp.) grasslands over sand plains. Although G, pulchra specimens were collected over $250 \mathrm{~km}$ apart, the dominant vegetation was similar at both sites: spinifex grasslands with mulga overstoreys. Gunawardenea linnati was also collected in spinifex grasslands, with Acacia and spinifex dominating the leaf litter.

Superficial similarities between these species and other arid zone Deltocephalinae, including Goniagnathus (Tribe Goniagnathini) (Fletcher and Zahniser 2008) and Arawa Knight 1975 (Tribe Athysanini) (Knight 1975) implies that short and squat shape, often with brachyptery, may be morphological adaptations associated with drier areas. Presumably a more spherical shape reduces the surface to volume ratio thereby reducing the area in direct contact with the environment.

The occurrence of brachypterous insects in harsh desert environments raises questions about how these species survive extended periods of dry conditions when plant material may be difficult to find or access. It is possible that they are capable of surviving for long periods as eggs in a dormant state until conditions are suitable for emergence and breeding. Of note here, above average rainfall occurred in the Gibson Desert the year before the collection of the $G$. pulchra holotype (B. Ward, pers. comm. 2008). In arid areas, dormancy of certain insects until particularly good conditions occur may explain why species such as Occiplanocephalus rauns Evans 1942 (Deltocephalinae: Deltocephalini) are rarely collected. Day and Fletcher (1994) note that R.E. Turner collected in inland areas of Western Australia in 1936 after some of the heaviest rainfall ever recorded in the region. Turner collected the only known specimens of $O$. ravus (one male, one female in $\mathrm{BMNH}$ ) and the reason he was able to collect such interesting material may have been because the rain event enabled the local plants to flower and dormant herbivorous life forms to emerge for breeding.

The apparently restricted distributions of these arid zone species indicates that they may warrant recognition as short-range endemic species and their response to disturbance requires further study to ensure that current land management programs are suitable for each species' survival.

\section{ACKNOWLEDGEMENTS}

We thank Shae Callan, Nihara Gunawardene and Prof. Jonathan Majer (Curtin University) for collecting the material used in this study. Surveys of Barrow Island were funded by Chevron Ltd and collecting in the Gibson Desert was funded by the Western Australian Dept of Environment and Conservation. Bruce Ward and Karl Brennan are thanked for suppling habitat information on sites where specimens were recovered at Gibson Desert and Lorna Glen Station, respectively. The Australian Biological Resources Study, a division of the Australian Government Department of the Environment and Heritage, has provided funding support to the first author to study Australian Deltocephalinae.

\section{REFERENCES}

Day, M.F. and Fletcher, M.J. (1994). An annotated catalogue of the Australian Cicadelloidea (Hemiptera: Auchenorrhyncha). Inertebrate Taxonomy 8: 1117 1288.

Fletcher M.J. (2004 \& updates). Identification kels and checklists for the leafloppers, planthoppers and their relatioes occurring in Australia and neighbouring areas (Hemiptera: Auchenomyncha). http://wwwagricnsw. govau/Hort/ascu/start.htm (Accessed 4th March 2008)

Fletcher, M.J. (2007). The identity of Pascoepus airidiceps (Evans) based on recognition of the male and a new species of Zaletta from Barrow Island, Western Australia (Hemiptera: Cicadellidae: Idiocerinae) General and Applied Entomology 36: 13-16.

Fletcher, M.J. (2008). An impressive new species of Enacanthella Evans from Western Australia (Hemiptera: Cicadellidae: Euacanthellinae). Gental and Applied Entomology 37: 15-19.

Fletcher, M.J. and Zahniser, J.N. (2008). The first record of Goniagnathini from Australia with description of four new species of Contumathe Fieber (Hemiptera: Cicadellidae: Deltocephatinae). Znotum 1692: 43-54

Harey, M.S. (2002). Short-range endemism among the Australian fauna: some examples from non-marine environments. Inested rate Systematicis 16: 555-570.

Knight, W.J. (1975). Deltocephalinae of New Zealand (Homoptera: Cicadellidae). New Zahant foum of Zoology 2(2): 169-208. 
Linnaeus, C. (1758). II. Hemiptera. Systema Naturae per regna tria naturae, secundum classes, ordines, genera, species, cum characteribus, differentiis, synonymis, locis. Ed.10. rev.1, 1-824.

Masters, P., Dickman, C.R. and Crowther, M. (2003). Effects of cover reduction on mulgara Dasycercus cristicauda (Marsupialia: Dasyuridae), rodent and invertebrate populations in central Australia: Implications for land management. Austral Ecology 28: 658-665.
Owens, G. (2004). Conserving biodiversity in the rangelands: Are land systems effective surrogates for spider assemblages? Honours thesis. Curtin University of Technology, Perth, Western Australia. 57 pp.

Manuscript received 20 March 2008; accepted 24 August 2008. 